\title{
Phytochemical and antioxidant studies of Cleome heratensis (Capparaceae) plant extracts
}

\author{
Mohammad Ali Nasseri, Soheila Behravesh, Ali Allahresani and Milad Kazemnejadi * (D)
}

\begin{abstract}
Background: In this research, different active phytochemical constituents present in Cleome heratensis (C. heratensis) from Capparaceae family were investigated. Moreover, the fatty acids present in the seed and aerial parts of the plant were identified by gas chromatography (GC) after esterification of the oil. Antioxidant activity of the aerial parts and seed of $C$. heratensis methanolic extract over 2,2'-diphenylpicryl-1-hydrazyl (DPPH) was investigated using ultravioletvisible (UV-Vis) spectrophotometer.

Methods: To study total phenolic compounds and flavonoids, the plant was extracted from ethanol by ultrasonic method, then further extracted with other solvents. Amounts of anthocyanins and tannins/condensed tannins were determined by their corresponding ethanolic and acetone extracts. Antioxidant activity of the plant species was studied by a spectrophotometric method using $80 \%$ methanolic extract.

Results: The high content of phenolics as $16.915 \mathrm{mg}$ tannic acid equivalents per gram of dry matter (TAE/g DM), tannins (12.231 mg TA/gr DM) and condensed tannins (4.086 mg TA/g DM) was obtained for the C. heratensis extract. The most flavonoids content was found 4.444 rutin equivalents (in $\mathrm{mg}$ ) per gram of dry matter (mg RE/g DM) in plant's aerial extract. The most amount of anthocyanin $(0.48 \mathrm{mmol} / \mathrm{gr} \mathrm{WM})$ was observed in flowering stage. Antioxidant activity of the aerial parts and seed of $C$. heratensis methanolic extract were 11.92 and $63.54 \mathrm{mg} / \mathrm{mL} \mathrm{IC}$, respectively.

Conclusion: High level of phenolic components including flavonoids, proanthocyanidins and tannins was detected in the extract of aerial parts of the plant. The oil of seed of this plant is a rich source of saturated and unsaturated fatty acids. Finally, C. heratensis aerial part extract was found as an excellent natural antioxidant.
\end{abstract}

Keywords: Cleome heratensis, Plant extract, Phytochemicals, Fatty acid, Antioxidant

\section{Background}

Natural products contain different valuable chemical components such as phenolic compounds, phthalides, phenylpropanoids, terpenoids, essential oils, aromatic compounds, alkaloids, alkynes, sterols, polysaccharides, fatty acids, anthocyanin, tannins, etc. (Oksman-Caldentey and Inze 2004; Picot et al. 2017; Mollica et al. 2015). They also have significant antioxidant activity (Embuscado 2015). Knowledge of these components in a plant

\footnotetext{
*Correspondence: miladkazemnejadi@birjand.ac.ir;

miladkazemnejad@yahoo.com

Department of Chemistry, Faculty of Sciences, University of Birjand, Birjand, Iran
}

not only helps for the quality control analysis of the plant but also manifests nature of the drug or formulation (Jain et al. 2011).

Phenolic compounds are one of the important groups of secondary metabolites of natural products that have a large diversity of structures and functions including water-soluble (flavonoids, phenolic acids, quinones, phenyl propanoids) and water-insoluble compounds (tannins, lignins condensed, cell-wall bound hydroxycinnamic acids) (Alu'datt et al. 2017; Mocan et al. 2016; Quispe et al. 2012; Nile et al. 2017). In this way, various biological effects have been found for phenolic compounds; they are known as antioxidants that could 
be served as free radical scavengers and protect oxidative damages (Zhu et al. 2017; Sreelatha and Padma 2009; Rauter et al. 2012; Haminiuk et al. 2012). Anti-inflammatory (Ambriz-Pérez et al. 2016) and antidiabetic (Ghorbani 2017) effects are another biological activities of phenolic compounds.

Tannins are one of the most important classes of polyphenols that are found in fruits and plants (Rauter et al. 2012). They are mostly present as phenolic polymers. Two main types of tannins are condensed and hydrolysable. Gallotannin or tannic acid is a type of hydrolysable tannin in fruits (Maia et al. 2017; Ma et al. 2017).

Anthocyanins are another class of flavonoids and the largest group of water-soluble natural pigments belonging to the polyphenolic family. They are responsible for the colors red, violet, and blue for many fruits, vegetables, and cereal grains (Hosseinian and Beta 2007). Theses bioactive molecules are widely spread in plant food. They show useful health effects, radical scavenging, chelation of heavy metals such as copper, zinc, and iron (Prior and Wu 2006; Ma et al. 2018). The chemical structure of the major compounds in a natural plant is shown in Fig. 1a-d.

Fatty acids (FAs) are another class of bioactive compounds that make up an important part of the human diet (de Koning et al. 2001). They could be classified into unsaturated and saturated fatty acids, which both play an inevitable role in human health and nutrition (Smith et al. 2013; Xiao et al. 2012). Also, poly-unsaturated fatty acids (PUFAs), as a health-supporting nutrients, have the unique medicinal and preventing properties toward inflammatory, heart diseases, atherosclerosis, autoimmune disorder, diabetes, eczema, dermatitis, asthma, rheumatoid arthritis, atherosclerosis, diabetes, obesityeven cancer and other diseases (Belch and Hill 2000; Leventhal et al. 1993; Sierra-Cantor and Guerrero-Fajardo 2017; Kaurinovic et al. 2011; Xiao et al. 2012; Ramadan et al. 2006). From this viewpoint, identification of total fatty acids and lipids in plant seems to be essential.

So, isolation and identification of these bioactive compounds in a plant are of utmost importance leading to further biological and pharmacologic investigations. These study might be served for developing the herbal drug that requires the isolate novel bioactive compounds from the medicinal plants, which may open a new route to cure various irremediable diseases such as diabetes and hepatitis (Azmir et al. 2013).

Cleome heratensis (C. heratensis) belongs to Cleomaceae family that includes more than 170 species of shrubs, herbaceous annual and perennial plants (Asemaneh et al. 2006). The genus $C$. heratensis is a flowering annual herbaceous plant which is typical of warm temperate areas during summer and autumn. Its well-known species include spider flowers, spider plants, spider weeds or bee plants (Pakdaman et al. 2013). The germinating, flowering and fruiting stage of this plant are in May, September and October, respectively (Ghaderian and Baker 2007). Various biological activities have been known for different species of Cleome (Singh et al. 2018), such as anti-microbial and insecticidal activities (Williams et al. 2003), anti-inflammatory (Puchchakayala et al. 2008), antioxidant (Narendhirakannan et al. 2007), hepatoprotective (Gupta and Dixit 2009). The aim of this research is focused on comprehensive assessment of phytochemical and fatty acid composition as well as antioxidant activity of different extracts from roots and aerial parts in different phenological periods of $C$. heratensis.

\section{Methods}

Plant and chemicals

Aerial part, root, and seed (Fig. 2) of C. heratensis were collected in late September and October 2014 from South Khozestan, Birjand, Iran at four stages of growth including: vegetative $\left(\mathrm{S}_{1}\right)$, pre-flowering $\left(\mathrm{S}_{2}\right)$, flowering $\left(\mathrm{S}_{3}\right)$ and fruiting stage $\left(\mathrm{S}_{4}\right)$ in May, early September, late September and October 2014, respectively. They were identified in the Herbarium of Agriculture Institute, Mashhad, Iran (Herbarium number: 5413). All the chemicals were of analytical reagent grade purchased from Sigma Aldrich and used as received without further purification.

Folin-Ciocalteu's (FC) phenol reagent, sodium carbonate anhydrous, sodium hydroxide, polyvinyl pyrrolidone (PVP), hydrochloric acid, acetate sodium, aluminum chloride hexahydrate, tannic acid, rutin and 2,2'-diphenylpicryl-1-hydrazyl were purchased from Sigma and Merck companies. Gallic acid was purchased from Fluka supplier.

\section{Instrumentation}

Analysis of the fatty acids was performed on a YL 6100 gas chromatograph system with a CBP5 column (Shimadzu $30 \mathrm{~m} \times 0.32 \mathrm{~mm} \times 0.25 \mathrm{~mm}$ ) equipped with an FID detector. Compounds were separated on a CP-Sil 88 Fusedsilica capillary column $(100 \mathrm{~m} \times 0.25 \mathrm{~mm} \times 0.2 \mu \mathrm{m})$. UV-Vis spectra were recorded on Shimadzu UV-Win $\mathrm{X}$-ma 2000 spectrophotometer at span $20-800 \mathrm{~nm}$.

\section{Fatty acid composition Extraction of seed oil}

To obtain the fatty acid components in C. heratensis seed, the dried ground seed of the plant (Fig. 2b) was extracted with $n$-hexane using a Soxhlet apparatus $\left(70{ }^{\circ} \mathrm{C}, 8 \mathrm{~h}, 5 \%\right.$ extraction yield). After removing $n$-hexane using a rotary evaporator, the obtained oily mixture 
a<smiles></smiles><smiles>O=C(OCC1OC2C(O)CC(OC(=O)c3cc(O)c(O)c(O)c3)(OC2O)C1O)c1cc(O)c(O)c(OC(=O)c2cc(O)c(O)c(O)c2)c1</smiles>

b<smiles>COc1c(O)cc(C2Oc3c(c(O)cc(O)c3C3c4c(O)cc(O)cc4OC(c4ccc(O)cc4)C3O)CC2O)cc1O</smiles>

Fig. 1 Basic structures of $\mathbf{a}$ anthocyanins, b proanthocyanidins, c tannins, d flavonoids
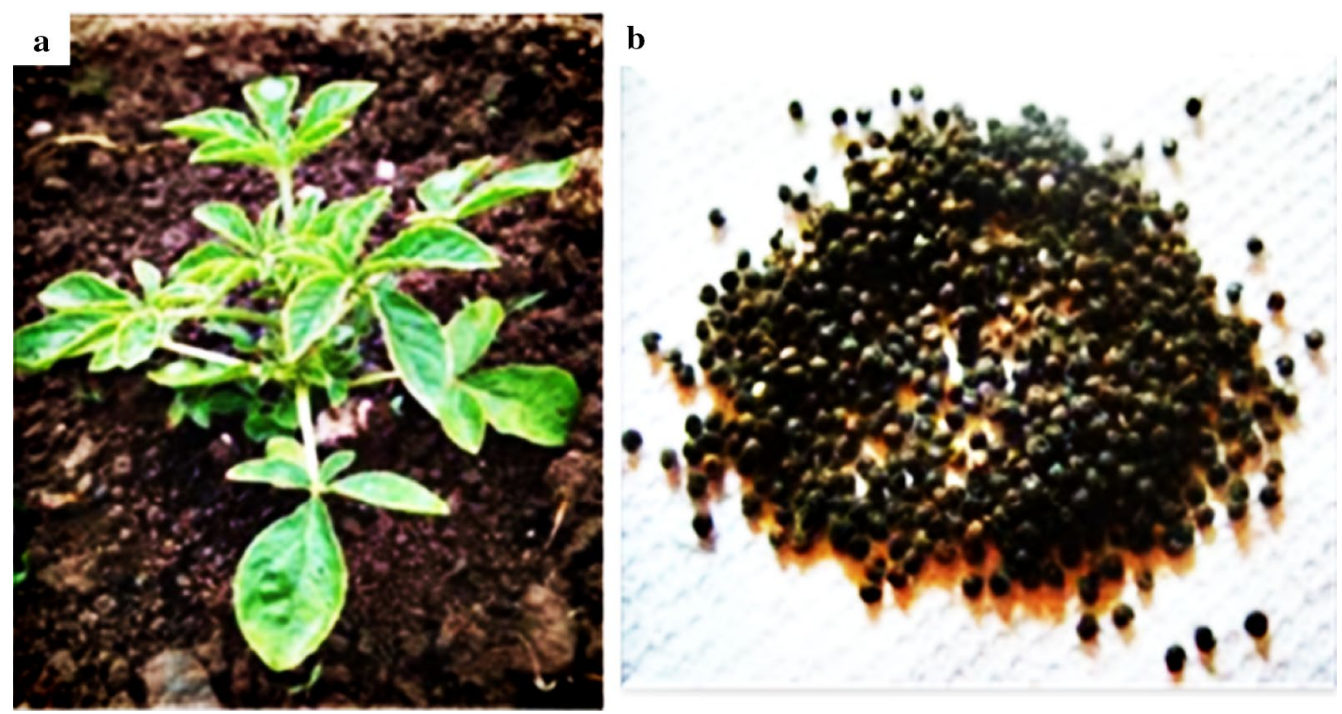

Fig. 2 a Aerial parts and $\mathbf{b}$ seed of $C$. heratensis

was treated with sodium methoxide, according to the Standard ISO 5509:2000 (ISO2000) to produce the corresponding methyl esters by the trans-esterification reaction (de Souza Schneider et al. 2004). Briefly, a drop of the obtained oil was dissolved in $n$-heptane $(1.0 \mathrm{~mL})$ and then, sodium methoxide $(50 \mu \mathrm{g})$ and water $(100 \mu \mathrm{L})$ were added to the mixture. The tube was centrifuged at $4500 \mathrm{rpm}$ for $10 \mathrm{~min}$ and the lower aqueous phase was separated after addition of $\mathrm{HCl}(50 \mu \mathrm{L}, 1.0 \mathrm{~mol}$ with methyl orange). Next, $20 \mathrm{mg}$ of sodium hydrogen 
sulphate was added to the solution and the mixture was centrifuged at $4500 \mathrm{rpm}$ for $10 \mathrm{~min}$. The resultant organic phase was transferred to a vial and injected to GC to identify its fatty acid composition.

\section{Determination of amounts of phenolic compounds Preparation of extracts}

Aerial parts (Fig. 1a) and stem of C. heratensis were rinsed with deionized water, air-dried at room temperature, then finely meshed and grinded with mortar and pestle, individually. Each plant powder (3.5 g) was extracted with ethanol (80\%) into an ultrasonic bath for $7 \mathrm{~min}$. The extracts were filtered, and the solvent was evaporated at reduced pressure. The yield of extractions was found $6 \%$ and $4 \%$ for the aerial and stem of the plant, respectively. The ethanolic extract was successively further extracted with four solvents with increasing polarity $\left(\mathrm{Et}_{2} \mathrm{O}, \mathrm{CHCl}_{3}, \mathrm{EtOAc}\right.$ and $\left.n-\mathrm{BuOH}\right)$. All five extracts were evaporated to dryness and then dissolved in $50 \%$ ethanol to make $1 \%(\mathrm{w} / \mathrm{v})$ solutions.

\section{Quantification of total phenolics content}

The amount of total phenolic content of the extracts was determined using the Folin-Ciocalteu colorimetric method according to the previously reported protocol (Chandra et al. 2014). Briefly, the method was performed by addition of $0.6 \mathrm{~mL}$ distilled water and $0.2 \mathrm{~mL}$ FolinCiocalteu reagent $(0.5 \mathrm{M})$ to an aliquot of plant extracts as well as standards. The mixture was stirred vigorously for $15 \mathrm{~min}$ and then, a solution of sodium carbonate $(1.0 \mathrm{~mL}, 8 \% \mathrm{w} / \mathrm{v})$ was added to the mixture. The mixture was further diluted to $3.0 \mathrm{~mL}$ and set it aside for $30 \mathrm{~min}$; then, the absorbance of the resulting blue-colored solution was measured at $760 \mathrm{~nm}$.

Quantitative determination of phenolic contents was performed based on the calibration curves of the standard samples with concentrations ranging from 20, 40, 50, 80 and $100 \mathrm{mg} / \mathrm{L}$ of gallic acid in 50\% ethanol. The results were expressed as gallic acid equivalents (GAE) in milligrams per gram of dry plant material weight $(\mathrm{mg} / \mathrm{g})$.

\section{Total flavonoids content}

The total content of flavonoids was measured quantitatively using rutin as a reference, according to the described procedure by Bousselsela et al. with a little modification (Brand-Williams et al. 1995). Briefly, in a dry tube, $1.0 \mathrm{~mL}$ of aluminum trichloride solution in $50 \%$ ethanol along with $3.0 \mathrm{~mL}$ sodium acetate $(10 \% \mathrm{w} / \mathrm{v})$ was added to the plant extract $(1.0 \mathrm{~mL})$. Then, the absorbance was recorded at $415 \mathrm{~nm}$ after $40 \mathrm{~min}$ of the mixing. Also, the absorbance of a reference solution, which was prepared by $1 \mathrm{~mL}$ of rutin solution instead of the plant extract, was read simultaneously. Rutin solution was prepared with addition of $10 \mathrm{~mL}$ of $50 \%$ ethanol to $0.005 \mathrm{~g}$ of dried rutin. Quantitative determination of flavonoids contents was performed using standard calibration curves using various rutin concentrations of 25, 50, 100 and $250 \mathrm{mg} / \mathrm{L}$. Finally, the flavonoids concentrations were reported as rutin equivalents in milligrams per gram of dry plant material weight (mg RE/gr DW).

\section{Analysis of anthocyanins}

Analysis of anthocyanins was conducted according to the method described by Hara et al. (2003). The fresh parts of $C$. heratensis $(0.2 \mathrm{~g})$ were extracted by rubbing with $3.0 \mathrm{~mL}$ of acidified methanol (MeOH: $\mathrm{HCl} ; 99: 1, \mathrm{v} / \mathrm{v})$. The crude extract was centrifuged at $6000 \mathrm{rpm}$ for $30 \mathrm{~min}$ and set it aside in dark (covered with an aluminum foil) overnight (yield of extraction: 1.1\%). The absorbance of the supernatant was recorded at $550 \mathrm{~nm}$ to detect anthocyanins.

\section{Analysis of tannin content}

The total tannins were determined using the three steps method reported by Makkar et al. (1993). Firstly, powdered samples $(200 \mathrm{mg}$ ) were extracted with $70 \%$ acetone. The yield of extractions was found 5\%, 4\% and 6\% for aerial, root and seed of the plant, respectively. The extract was centrifuged at $3000 \mathrm{rpm}$ for $5 \mathrm{~min}$ and then filtered. The first step involves the preparation of calibration curves of the standard samples with concentrations ranging from 20, 40, 50, 80 and $100 \mathrm{mg} / \mathrm{L}$ of tannic acid in $50 \%$ ethanol. In the second step, the mixture of extract $(1.0 \mathrm{~mL})$, distilled water $(1.0 \mathrm{~mL})$ and PVP $(0.1 \mathrm{~g})$ was shaken for $5 \mathrm{~min}$, incubated for $10 \mathrm{~min}$ at $4{ }^{\circ} \mathrm{C}$, and then centrifuged. The total phenolic compounds without tannins were also determined by standard calibration curves of tannic acid. At last, tannins were determined by the difference between total phenolic compounds before and after the addition of PVP.

\section{Determination of condensed tannins (Proanthocyanidins)}

$200 \mathrm{mg}$ of powdered samples (aerial, root, seed) was extracted with $70 \%$ acetone followed by ultra-sonication at $3000 \mathrm{rpm}$ for $20 \mathrm{~min}$ at room temperature. Then, the extract was centrifuged for $10 \mathrm{~min}$ at $3000 \mathrm{rpm}$. The supernatant was collected and kept on ice. The yield of extractions was found $5 \%, 4 \%$ and $6 \%$ for aerial, root and seed of the plant, respectively.

The amount of proanthocyanidins in extracts was measured according to the method described by Porter et al. (1985). Briefly, in first, acidified butanol reagent (butanol-HCI (37\%) 95:5 v/v) was prepared by mixing $950 \mathrm{~mL}$ of $n$-butanol with $50 \mathrm{~mL}$ concentrated $\mathrm{HCl}$ 
(37\%). Ferric reagent was prepared by dissolving $2.0 \mathrm{~g}$ of ferric ammonium sulfate in $2 \mathrm{~N} \mathrm{HCl}$. In a glass test tube, $3 \mathrm{~mL}$ of the butanol- $\mathrm{HCl}$ reagent along with $0.1 \mathrm{~mL}$ of the ferric reagent was added to $0.5 \mathrm{~mL}$ of the tannin extract diluted with $70 \%$ acetone. This amount of acetone was used to prevent exceeding the absorbance from 0.6 (Porter et al. 1985). The tubes were capped with a glass marble, then shaken using a Vortex and placed in a boiling water bath for $1 \mathrm{~h}$. After cooling the tubes, their absorbance was recorded at $550 \mathrm{~nm}$. The absorbance of the unheated mixture (considered as a suitable blank) was subtracted from the absorbance of heated mixture. The absorption band at $550 \mathrm{~nm}$ was used for calculation of the condensed tannins. If the development of pink color without heating happened, one heated blank will be used for each sample containing $0.5 \mathrm{~mL}$ of the extract, $3 \mathrm{~mL}$ of butanol and $0.1 \mathrm{~mL}$ of the ferric reagent (Seabra et al. 2018). The condensed tannins (\% in dry matter) as leucocyanidin equivalent were calculated using the following equation (Ben Ahmed et al. 2017):

$$
\text { Condensed tannins }=\frac{\mathrm{A}(550 \mathrm{~nm}) \times \text { Dillution factor }}{\% \text { Dry matter }}
$$

Given that the extract was prepared from $70 \%$ acetone, the dilution factor is calculated by the following formula (Ben Ahmed et al. 2017):

$$
\text { Dilution factor }=\frac{0.5 \mathrm{~mL}}{\text { Volume of extract taken }}
$$

The dry matter was determined according to the following procedure: Sample (5 g) was placed into an oven adjusted at $100-105{ }^{\circ} \mathrm{C}$ to complete drying and to reach a constant weight. After cooling to room temperature, weight of the dried sample was recorded and then, \% dry matter was calculated by the following formula: Dry matter $(\%)=W_{2} / W_{1} \times 100$, where $W_{2}$ and $W_{1}$ are mass $(\mathrm{g})$ of the sample before and after drying.

\section{Antioxidant capacity \\ Extraction}

Approximately, $0.15 \mathrm{~g}$ of dried parts of $C$. heratensis with $3 \mathrm{~mL}$ of $80 \%$ methanol was extracted at ambient temperature for $45 \mathrm{~min}$ under an ultrasonic wave. Then, the extracts were kept in the dark for $15 \mathrm{~min}$ and were centrifuged for $15 \mathrm{~min}$ at $5000 \mathrm{rpm}$. After centrifugation, the supernatants were collected. The extracts were kept at $4{ }^{\circ} \mathrm{C}$ in dark until further analysis (yield of extraction: $7 \%$ ).

\section{DPPH radical scavenging activity}

The ability of the $C$. heratensis extracts towards hydrogen atom- or an electron donation was determined using the bleaching of the DPPH methanol solution as a reagent; then the antioxidant capacity of the extracts was measured by a spectrophotometric assay (Brand-Williams et al. 1995). Different concentrations of the extract were prepared and for each experiment, $75 \mu \mathrm{L}$ plant extract was added to $3.9 \mathrm{~mL}$ of $0.00463 \mathrm{~g} / \mathrm{L} \mathrm{DPPH}$ solution. The final solution was protected with an aluminum foil to prevent from light. After vigorous shaking of the solution, it was left for $30 \mathrm{~min}$ (incubation period) at ambient temperature; then the absorbance was read at $517 \mathrm{~nm}$. The percent of the remaining radicals at $30 \mathrm{~min}$ was calculated using the following equation:

$$
\text { Antiradical activity }(\%)=\frac{A_{c}-A_{s}}{A_{c}} \times 100,
$$

where $A_{c}$ and $A_{s}$ are the absorbance of the control (consist of solvent and DPPH) and the sample extract, respectively. Methanol and ascorbic acid were used as blank and positive control, respectively. All of the experiments were repeated for three times and their average was reported. The $\mathrm{IC}_{50}$ values were calculated by plotting the inhibition percentage against the concentration of the extract (Muthukrishnan and Manogaran 2018). Different concentrations $(1 / 10,1 / 20,1 / 30,1 / 40)$ of the aqueous extract of $C$. heratensis were prepared by boiling $1 \mathrm{~g}$ of aerial parts of the plant in 10,20,30, $40 \mathrm{~mL}$ of deionized water for $5 \mathrm{~min}$. $\mathrm{IC}_{50}$ is the required initial concentration of a selected antioxidant sample (plant extract in this study) to quench $50 \%$ of the free radicals in the reaction mixture.

\section{Results and discussion}

\section{Fatty acid composition}

The fatty acid composition of oil is a major indicator of oil quality; oils with high percentages of unsaturated fatty acids, mainly oleic and linoleic, are of high quality (Jokić et al. 2013). The fatty acid composition of the C. heratensis seed extract was determined by GC analysis (Fig. 3). The oil content of seeds can be varying from around $1 \%$ in rice to more than 55\% in Myristicaceae; the oil content in $C$. heratensis seed extract was found $27.47 \%$. The analysis of fatty acid obtained from seed extract of $C$. heratensis revealed the presence of over 8 different compounds as shown in Fig. 3 and Table 1. The major components were linoleic acid (67.8\%), oleic acid (17.8\%) and palmitic acid (8.7\%).

The results demonstrated that the amount of unsaturated fatty acids (87.8\%) was higher than saturated fatty acids (12.2\%). The ratio of unsaturated to saturated fatty acids (U:S) was 7.20 in this oil. The fatty acid composition of $C$. heratensis seed with other edible vegetable oils was compared (Table 2). According to Table 2, the U/S ratio which is obtained for our plant was higher than olive and corn oil. Therefore, considering that the higher ratio of 


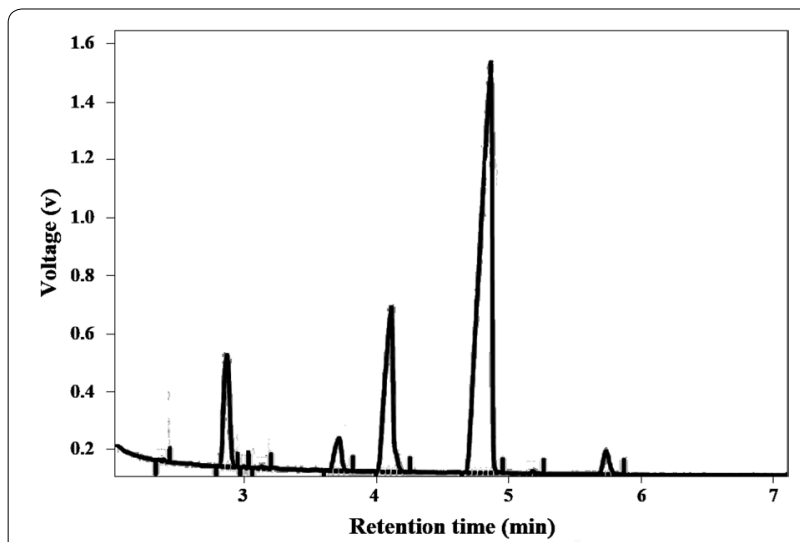

Fig. 3 Chromatogram of fatty acids in C. heratensis seed extract. (YL 6100 gas chromatograph system with a CBP5 column (Shimadzu $30 \mathrm{~m} \times 0.32 \mathrm{~mm} \times 0.25 \mathrm{~mm}$ ) equipped with an FID detector)

$\mathrm{U}: \mathrm{S}$ for oil is safer for the heart and blood vessels, it proposes that these seeds are examined for feed intake.

More importantly, the amount of linolenic acid, as an essential fatty acid in human food nutrition, was found $67.8 \%$, which is higher than the most vegetable oils (Table 2 ).

\section{Phenolic composition}

\section{Total phenolics content}

The results obtained from the determination of the total phenolic content of $C$. heratensis extracts are summarized in Table 3. As shown in Table 3, the total phenols content of the $C$. heratensis extract depends on harvesting time in various solvents.

The concentration of total phenols of $C$. heratensis extracts was measured as gallic acid equivalents in milligrams per gram of dry plant material weight (mg GAE/g DW). The results showed that in most cases, the quantities of phenolic compounds of the plant were increased in different solvents during various developmental stages. The higher content was detected in acetone extract of aerial part (16.915 mg TAE/g DM) in $\mathrm{S}_{4}$ (fruiting stage) and the lowest total phenolic level was seen in ether extract of the root $\left(0.048 \mathrm{mg}\right.$ GAE/g DM) in $\mathrm{S}_{2}$ (Preflowering stage). Also, the highest amount $(19.0377 \mathrm{mg}$ TAE/g DM) was observed in the acetone extract of the seed. In general, the highest total phenolic content was detected in aerial parts and extraction by acetone has a maximum output.

Table 1 Fatty acid composition of seed oil of the C. heratensis seed

\begin{tabular}{lllll}
\hline Entry & Fatty acid & Type & Retention time (min) & Content (\%) \\
\hline 1 & Myristic acid $\left(C_{14: 0}\right)^{\text {a }}$ & Saturated & 2.383 & 0.2 \\
2 & Palmitic acid $\left(C_{16: 0}\right)$ & Saturated & 2.867 & 8.7 \\
3 & Stearic acid $\left(C_{18: 0}\right)$ & Saturated & 3.717 & 3.1 \\
4 & Arachidic acid $\left(C_{20: 0}\right)$ & Saturated & 5.117 & 0.2 \\
5 & Palmitoleic acid $\left(C_{16: 1}\right)$ & Unsaturated $(\omega-7)$ & 3.140 & 0.2 \\
6 & Oleic acid $\left(C_{18: 1}\right)$ & Unsaturated $(\omega-9)$ & 4.113 & 17.8 \\
7 & Linoleic acid $\left(C_{18: 2}\right)$ & Unsaturated $(\omega-6)$ & 5.867 & 67.8 \\
8 & a-Linoleic acid $\left(C_{18: 3}\right)$ & Unsaturated $(\omega-3)$ & 5.737 & 2.0 \\
\hline
\end{tabular}

a Saturated carbon: unsaturated carbon

Table 2 Comparison of fatty acids composition of C. heratensis seed with the various vegetable oils (Katragadda et al. 2010)

\begin{tabular}{|c|c|c|c|c|c|}
\hline Type & Saturated & Mono unsaturated & Total poly unsaturated & $U / S^{a}$ & Linoleic acid (\%) \\
\hline Coconut & 91.00 & 6.00 & 3.00 & 0.1 & 2 \\
\hline Corn & 12.95 & 27.58 & 54.68 & 6.35 & 59 \\
\hline Cottonseed & 25.90 & 17.80 & 51.90 & 2.69 & 54 \\
\hline Olive & 14 & 72 & 14 & 6.14 & $3.5-21$ \\
\hline Soybean & 15.65 & 22.78 & 57.74 & 5.14 & 51 \\
\hline Sunflower (60\% linoleic) & 10.1 & 45.4 & 40.1 & 8.46 & 10 \\
\hline Sunflower (70\% Oleic) & 9.86 & 83.69 & 3.80 & 8.87 & - \\
\hline Seed of C. heratensis & 12.2 & 18 & 69.8 & 7.20 & 67.8 \\
\hline
\end{tabular}

a Unsaturated/saturated fatty acids 
Table 3 The amounts of phenolic compounds in the tissues extracts of the C. heratensis (mg GAE/g DM ${ }^{\mathrm{a}}$ )

\begin{tabular}{llllllrr}
\hline Sample & Harvesting time & $\mathbf{H}_{\mathbf{2}} \mathbf{O}$ & $\boldsymbol{n}$-BuOH & EtOAc & Chloroform & Ether & Acetone $^{\mathbf{b}}$ \\
\hline Aerial parts & $\mathrm{S}_{2}$ & 0.730 & 1.605 & 0.455 & 0.405 & 0.270 & 10.5426 \\
& $\mathrm{~S}_{3}$ & 0.866 & 4.596 & 0.445 & 0.199 & 0.316 & 7.1247 \\
& $\mathrm{~S}_{4}$ & 2.934 & 7.558 & 0.528 & 0.139 & 0.425 & 16.9146 \\
\multirow{2}{*}{ Root } & $\mathrm{S}_{2}$ & 3.394 & 0.165 & 0.282 & 0.057 & 0.048 & 1.8299 \\
& $\mathrm{~S}_{3}$ & 1.159 & 0.272 & 0.207 & 0.080 & 0.079 & 1.6642 \\
& $\mathrm{~S}_{4}$ & 1.046 & 0.355 & 0.369 & 0.218 & 0.009 & 2.7589 \\
Seed & - & 1.054 & 0.758 & 0.435 & 0.190 & & 0.452 \\
\hline
\end{tabular}

a mg gallic acid equivalents per gram of dry matter

b As tannic acid equivalents (TAEs)

Table 4 The amounts of flavonoids compounds in the tissues extracts of the $C$. heratensis (mg RE/g DM ${ }^{a}$ )

\begin{tabular}{lllllll}
\hline Sample & Harvesting time & $\mathbf{H}_{\mathbf{2}} \mathbf{O}$ & $\boldsymbol{n}$-BuOH & EtOAc & Chloroform & Ether \\
\hline Aerial parts & $\mathrm{S}_{2}$ & 0.405 & 2.256 & 0.514 & 0.193 & 0.350 \\
& $\mathrm{~S}_{3}$ & 0.389 & 2.956 & 0.504 & 0.136 & 0.399 \\
& $\mathrm{~S}_{4}$ & 1.417 & 4.444 & 0.541 & 0.113 & 0.387 \\
Root & $\mathrm{S}_{2}$ & 0.476 & 0.517 & 0.156 & 0.020 & 0.023 \\
& $\mathrm{~S}_{3}$ & 0.477 & 0.221 & 0.483 & 0.103 & 0.158 \\
& $\mathrm{~S}_{4}$ & 0.786 & 0.324 & 0.280 & 0.152 & 0.244 \\
\hline
\end{tabular}

a Rutin equivalents in milligrams per gram of dry plant material weight

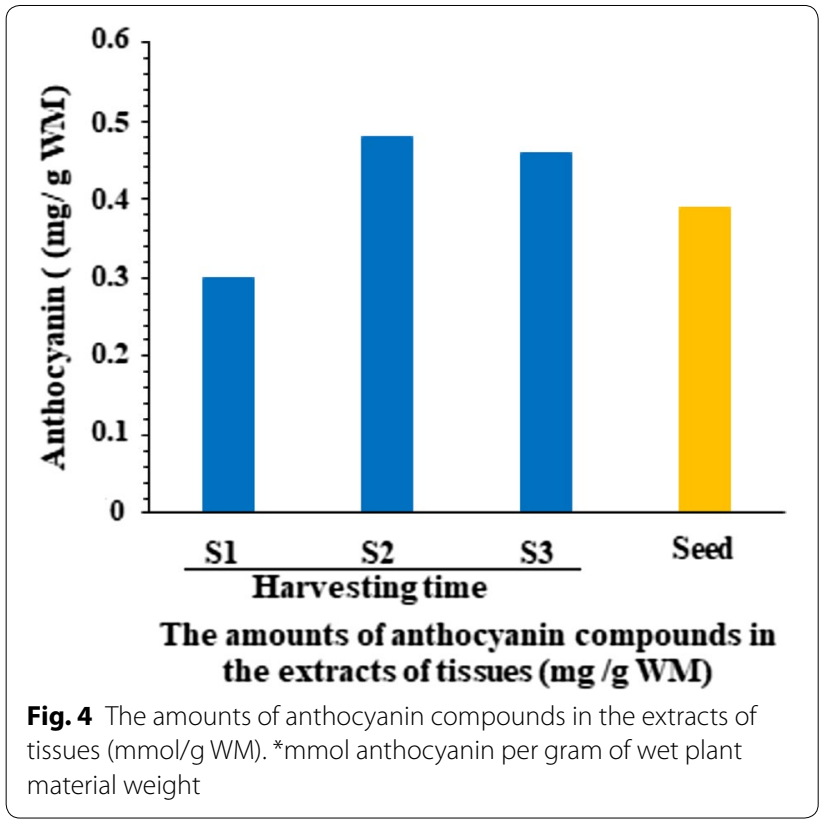

\section{Flavonoids content}

The concentrations of flavonoids of $C$. heratensis extract were determined as rutin equivalents in milligrams per gram of dry plant material weight (mg RE/g DW). The results showed that the amount of flavonoid compounds of the plant was increased in different solvents at different stages of growth (Table 4).

The highest flavonoids content was detected in $n$ - $\mathrm{BuOH}$ extract of the aerial part (4.444 $\mathrm{mg} \mathrm{RE} / \mathrm{g} \mathrm{DM}$ ) in $\mathrm{S}_{4}$ (fruiting stage) and the lowest content was seen in ether extract of the root $(0.003 \mathrm{mg} R E / g r \mathrm{DM})$ in $\mathrm{S}_{2}$ (Pre flowering stage) (Table 4). In general, similar to phenolic compounds, the highest content of flavonoids was detected in the aerial part at fruiting stage. Also, extraction by $n-\mathrm{BuOH}$ and acetone provides a maximum output, respectively.

\section{Anthocyanin content}

As shown in Fig. 4, concentration of anthocyanin of C. heratensis extract was measured as millimole per gram of wet plant material weight $(\mathrm{mmol} / \mathrm{g} W M)$. The results showed that in the primary stages, the anthocyanin amount increased and at the flowering stage $\left(\mathrm{S}_{3}\right)$, it reached to $0.48 \mathrm{mmol} / \mathrm{g} \mathrm{WM}$, and then decreased. In general, these results showed that extraction at flowering stage has maximum output due to flowers. Also, seed of the plant demonstrated $0.39 \mathrm{mmol} / \mathrm{g}$ WM anthocyanin which is higher than aerial parts of the plant. 


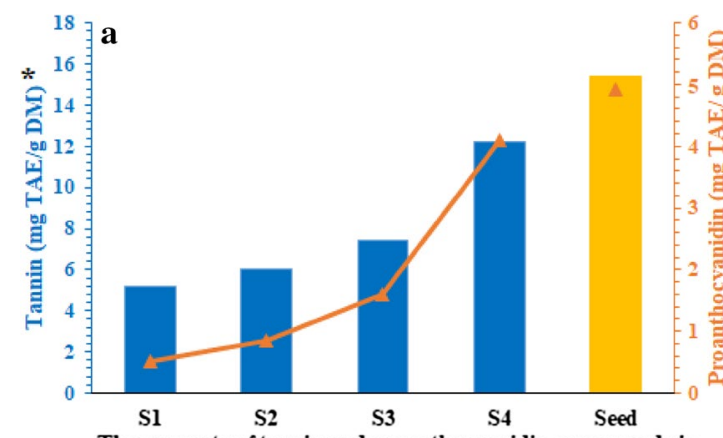

The amounts of tannin and proanthocyanidin compounds in the acetone extracts of the aerial parts and seed at various

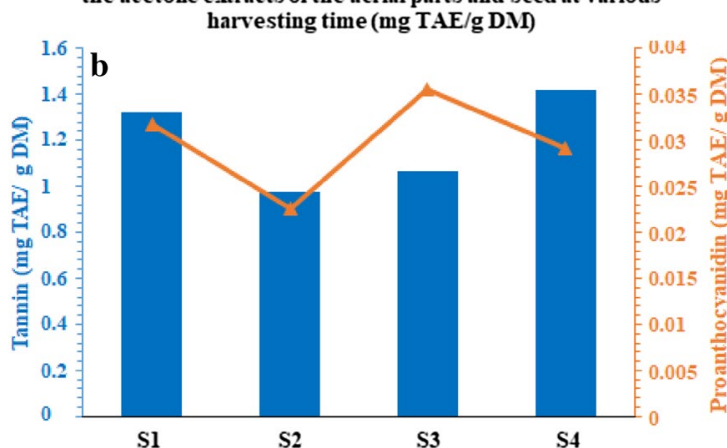

The amounts of tannin and proanthocyanidin compounds in the acetone extracts of the aerial parts at various harvesting time (mg TAE/g DM)

Fig. 5 The amounts of tannin (blue columns) and proanthocyanidin (yellow curves) and seed (yellow column) compounds in the tissues acetone extracts of the C. heratensis (mg TAE/g DM).*Tannin/ proanthocyanidin

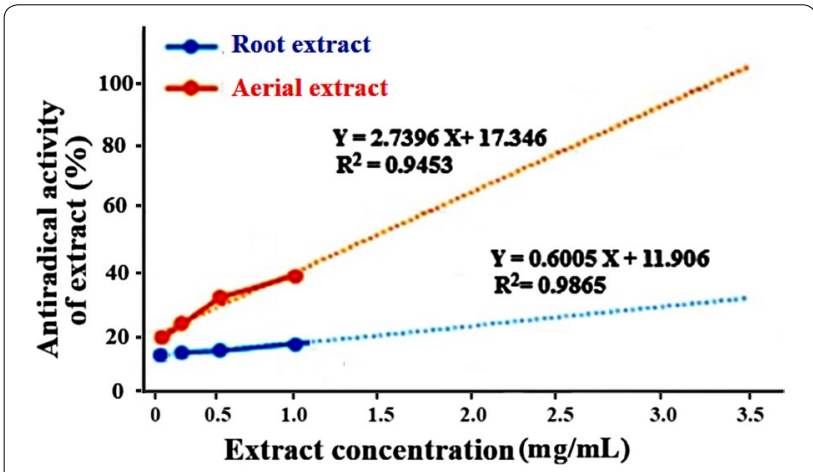

Fig. 6 Linear relationship between inhibition percentage of the extract and extract concentration

\section{Tannin and proanthocyanidin contents}

The concentrations of total and condensed tannins (proanthocyanidins) in the extracts of $C$. heratensis (mg TAE/g DM) are shown in Fig. 5. The results showed that the amount of tannins in aerial parts of the plant was increased during various developmental stages from $\mathrm{S}_{1}$ to $\mathrm{S}_{4}$. The highest content was detected in extract of aerial part in $\mathrm{S}_{4}$ (fruiting stage) including total tannins (12.2312 mg TAE/g DM) and proanthocyanidin (4.0856 $\mathrm{mg}$ TAE/g DM). The lowest amount was seen in the extract of root in $\mathrm{S}_{2}$ equal to $0.9757,0.0226 \mathrm{mg} \mathrm{TAE} / \mathrm{g}$ DM for total and condensed tannin, respectively. In general, similar to other identified compounds, the highest contents were detected in the seed.

The differential accumulation of phenolic compounds in $C$. heratensis extracts at the different stages could be related to physiological changes during growth in response to environmental stress. The season, sunlight duration, UV radiation, and temperature are known parameters that affect the plant metabolism, since some compounds may be accumulated at a particular period to respond to environmental changes (Generalić et al. 2011; Negrão et al. 2017; Lu et al. 2017).

\section{Determination of antioxidant capacities}

Antioxidant activity of the $C$. heratensis extracts was determined using DPPH radical scavenging assay. This assay is based on hydrogen/electron transfer from a given antioxidant to DPPH. The DPPH has a strong absorption band at $\lambda_{\max }=517 \mathrm{~nm}$ with deep purple color, whereas the redacted product is yellowish without any absorption band (Lu et al. 2017). Although $\mathrm{DPPH}-\mathrm{H}$ is the final product, other complexes could be formed by reacting DPPH and oxidized intermediates in the extract and generate high molecular weight polymers (Pedan et al. 2016). The results from antioxidant property of the extract revealed the radical scavenging of the aerial and root extract of $C$. heratensis. Figure 6 shows the curve of inhibition percentage of the extract versus extract concentration as $\mathrm{IC}_{50}$ $(\mathrm{mg} / \mathrm{mL})$. As shown in the figure, the extract of aerial parts $(11.92 \mathrm{mg} / \mathrm{mL})$ exhibited higher scavenging activity than the roots extract $(63.44 \mathrm{mg} / \mathrm{mL})$. According to the definition of $\mathrm{IC}_{50}$, the lower $\mathrm{IC}_{50}$ value refers to a stronger antioxidant activity in a testing sample. Thus, aerial parts of the plant have higher antioxidant activity.

Figure 7 shows the UV-Vis spectra of DPPH solution before and after the addition of the aerial $C$. heratensis extract. The spectra clearly demonstrated the antioxidant activity of the extract with the complete elimination of the absorption band at $\lambda_{\max }=517 \mathrm{~nm}$ for DPPH (Fig. 7a). Figure 7b shows UV-Vis spectra recorded for aerial parts of $C$. heratensis extract. Electronic spectra of the extract showed one absorption band at $305 \mathrm{~nm}$ (Fig. 7b).

\section{Conclusions}

The C. heratensis from Capparaceae family is found mainly in the eastern region (Birjand) of Iran. The seed oil of this plant $(27.47 \%)$ is a rich source of unsaturated 

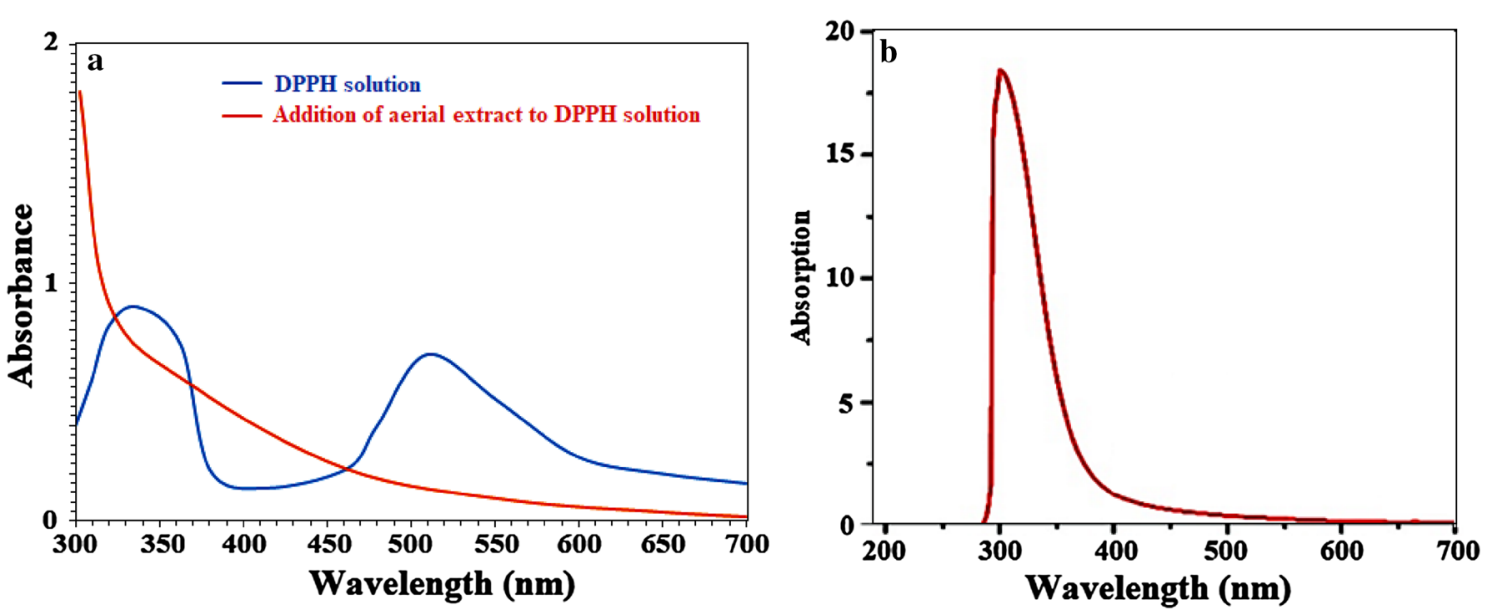

Fig. 7 a Antiradical activity of the aerial extract of C. heratensis $(0.1 \mathrm{~g} / \mathrm{mL})$ over quenching 2,2'-diphenylpicryl-1-hydrazyl (DPPH) radicals at room temperature. $\mathbf{b} \cup V$-visible spectra of aerial part of $\mathbf{C}$. heratensis extract

fatty acids (87.8\%), especially linoleic acid (67.8\%) and oleic acid (17.8\%). The highest total amounts of phenolic (16.915 mg TAE/g DM), flavonoids (4.444 mg RE/g DM), total tannins (12.231 mg TA/gr DM) and proanthocyanidins ( $4.086 \mathrm{mg} \mathrm{TA} / \mathrm{g} \mathrm{DM}$ ) components were detected in extract of aerial parts in fruiting stage and seed of the plant. Also, the most amount of anthocyanin $(0.48 \mathrm{mmol} /$ gr WM) was observed in flowering stage. Harvesting $C$. heratensis at the fruiting stage and extracting of aerial parts of plant or seeds by acetone give the most amounts of bioactive compounds. C. heratensis extract is a good natural antioxidant that could be added as a chemical basis in food and therapeutics.

\section{Abbreviations}

Cleome heratensis: C. heratensis; GC: gas chromatography; FA: fatty acids; PUFA: poly unsaturated fatty acid; FC: folin-ciocalteau's; PVP: polyvinyl pyrrolidone; DPPH: 2,2'-diphenylpicryl-1-hydrazyl; DM: dry matter; RE: rutin equivalents; TAE: tannic acid equivalents; GAE: gallic acid equivalents.

\section{Authors' contributions}

MAN and AA design the study. SB and MK performed the research experiments, acquired the data and wrote the manuscript. All authors were involved in the analysis and approved the final manuscript of publication. MAN and SB interpreted the results. All authors read and approved the final manuscript.

\section{Acknowledgements}

The authors are thankful to Research Council of University of Birjand for providing all the necessary facilities to carry out the research work.

\section{Competing interests}

The authors declare that they have no competing interests.

\section{Availability of data and materials}

All data that are relevant to the study are reported within the article.

\section{Consent for publication}

The authors approved the consent for publishing the manuscript.
Ethics approval and consent to participate

All the authors have read and agreed the ethics for publishing the manuscript.

Funding

No funding was received for this article.

\section{Publisher's Note}

Springer Nature remains neutral with regard to jurisdictional claims in published maps and institutional affiliations.

Received: 13 November 2018 Accepted: 25 January 2019

Published online: 06 February 2019

\section{References}

Alu'datt MH, Rababah T, Alhamad MN, Al-Mahasneh MA, Almajwal A, Gammoh S, Ereifej K, Johargy A, Alli I (2017) A review of phenolic compounds in oil-bearing plants: distribution, identification and occurrence of phenolic compounds. Food Chem 218:99-106

Ambriz-Pérez DL, Leyva-López N, Gutierrez-Grijalva EP, Heredia JB (2016) Phenolic compounds: natural alternative in inflammation treatment. a review. Cogent Food Agric 2:1131412

Asemaneh T, Ghaderian SM, Crawford SA, Marshall AT, Baker AJM (2006) Cellular and subcellular compartmentation of $\mathrm{Ni}$ in the Eurasian serpentine plants Alyssum bracteatum, Alyssum murale (Brassicaceae) and Cleome heratensis (Capparaceae). Planta 225:193-202

Azmir J, Zaidul ISM, Rahman MM, Sharif KM, Mohamed A, Sahena F, Jahurul MHA, Ghafoor K, Norulaini NAN, Omar AKM (2013) Techniques for extraction of bioactive compounds from plant materials: a review. J Food Eng 117:426-436

Belch JJ, Hill A (2000) Evening primrose oil and borage oil in rheumatologic conditions. Am J Clin Nutr 71:352s-356s

Ben Ahmed Z, Yousfi M, Viaene J, Dejaegher B, Demeyer K, Mangelings D, Vander Heyden Y (2017) Seasonal, gender and regional variations in total phenolic, flavonoid, and condensed tannins contents and in antioxidant properties from Pistacia atlantica ssp. leaves. Pharm Biol 55:1185-1194

Brand-Williams W, Cuvelier ME, Berset CLWT (1995) Use of a free radical method to evaluate antioxidant activity. LWT Food Sci Technol 28:25-30

Chandra S, Khan S, Avula B, Lata H, Yang MH, ElSohly MA, Khan IA (2014) Assessment of total phenolic and flavonoid content, antioxidant properties, and yield of aeroponically and conventionally grown leafy vegetables and fruit crops: a comparative study. Evid Based Complement Altern Med 2014:1-9 
de Koning S, van der Meer B, Alkema G, Janssen HG, Udo A (2001) Automated determination of fatty acid methyl ester and cis/trans methyl ester composition of fats and oils. J Chromatogr A 922:391-397

de Souza Schneider RC, Baldissarelli VZ, Trombetta F, Martinelli M, Caramão EB (2004) Optimization of gas chromatographic-mass spectrometric analysis for fatty acids in hydrogenated castor oil obtained by catalytic transfer hydrogenation. Anal Chim Acta 505:223-226

Embuscado ME (2015) Spices and herbs: natural sources of antioxidants-a mini review. J Funct Foods 18:811-819

Generalić I, Skroza D, Ljubenkov I, Katalinić A, Burčul F, Katalinić V (2011) Influence of the phenophase on the phenolic profile and antioxidant properties of Dalmatian sage. Food Chem 127:427-433

Ghaderian SM, Baker AJM (2007) Geobotanical and biogeochemical reconnaissance of the ultramafics of Central Iran. J Geochem Explor 92:34-42

Ghorbani A (2017) Mechanisms of antidiabetic effects of flavonoid rutin. Biomed Pharmacother 96:305-312

Gupta NK, Dixit VK (2009) Evaluation of hepatoprotective activity of Cleome viscosa Linn. extract. Indian J Pharmacol 41:36-40

Haminiuk CW, Maciel GM, Plata-Oviedo MS, Peralta RM (2012) Phenolic compounds in fruits-an overview. Int J Food Sci Technol 47:2023-2044

Hara M, Oki K, Hoshino K, Kuboi T (2003) Enhancement of anthocyanin biosynthesis by sugar in radish (Raphanus sativus) hypocotyl. Plant Sci 164:259-265

Hosseinian FS, Beta T (2007) Saskatoon and wild blueberries have higher anthocyanin contents than other Manitoba berries. J Agric Food Chem 55:10832-10838

Jain V, Murugananthan G, Deepak M, Viswanatha GL, Manohar D (2011) Isolation and standardization of various phytochemical constituents from methanolic extracts of fruit rinds of Punica granatum. Chin J Nat Med 9:414-420

Jokić S, Sudar R, Svilović S, Vidović S, Bilić M, Velić D, Jurković V (2013) Fatty acid composition of oil obtained from soybeans by extraction with supercritical carbon dioxide. Czech J Food Sci 31:116-125

Katragadda HR, Fullana A, Sidhu S, Carbonell-Barrachina ÁA (2010) Emissions of volatile aldehydes from heated cooking oils. Food Chem 120:59-65

Kaurinovic B, Popovic M, Vlaisavljevic S, Trivic S (2011) Antioxidant capacity of Ocimum basilicum L. and Origanum vulgare L. extracts. Molecules 16:7401-7414

Leventhal LJ, Boyce EG, Zurier RB (1993) Treatment of rheumatoid arthritis with gammalinolenic acid. Ann Intern Med 119:867-873

Lu Y, Wu N, Fang Y, Shaheen N, Wei Y (2017) An automatic on-line 2, 2-diphenyl-1-picrylhydrazyl-high performance liquid chromatography method for high-throughput screening of antioxidants from natural products. J Chromatogr A 1521:100-109

Ma H, Xu J, DaSilva NA, Wang L, Wei Z, Guo L, Johnson SL, Lu W, Xu J, Gu Q, Seeram NP (2017) Cosmetic applications of glucitol-core containing gallotannins from a proprietary phenolic-enriched red maple (Acer rubrum) leaves extract: inhibition of melanogenesis via down-regulation of tyrosinase and melanogenic gene expression in B16F10 melanoma cells. Arch Dermatol Res 309:265-274

Ma H, Johnson SL, Liu W, DaSilva NA, Meschwitz S, Dain JA, Seeram NP (2018) Evaluation of polyphenol anthocyanin-enriched extracts of blackberry, black raspberry, blueberry, cranberry, red raspberry, and strawberry for free radical scavenging, reactive carbonyl species trapping, anti-glycation, anti- $\beta$-amyloid aggregation, and microglial neuroprotective effects. Int J Mol Sci 19:461-480

Maia IRDO, Trevisan MTS, Silva MGDV, Breuer A, Owen RW (2017) Content of total phenolic compounds, flavonoids and tannins in methanol extracts of the genus Senna Mill. from the northeast of Brazil and evaluation of antioxidant capacity. J Pharmacogn Phytochem 6:1321-1325

Makkar HP, Blümmel M, Borowy NK, Becker K (1993) Gravimetric determination of tannins and their correlations with chemical and protein precipitation methods. J Sci Food Agric 61:161-165

Mocan A, Zengin G, Crişan G, Mollica A (2016) Enzymatic assays and molecular modeling studies of Schisandra chinensis lignans and phenolics from fruit and leaf extracts. J Enzyme Inhib Med Chem 31:200-210

Mollica A, Costante R, Akdemir A, Carradori S, Stefanucci A, Macedonio G, Ceruso M, Supuran CT (2015) Exploring new Probenecid-based carbonic anhydrase inhibitors: synthesis, biological evaluation and docking studies. Bioorg Med Chem 23:5311-5318

Muthukrishnan S, Manogaran P (2018) Phytochemical analysis and free radical scavenging potential activity of Vetiveria zizanioides Linn. J Pharmacogn Phytochem 7:1955-1960
Narendhirakannan RT, Subramanian S, Kandaswamy M (2007) Evaluation of antioxidant potential of Cleome gynandra L. leaf extract on the components of the lymphoid organs in adjuvant induced arthritis in rats. Int J Biol Chem 1:1-10

Negrão S, Schmöckel SM, Tester M (2017) Evaluating physiological responses of plants to salinity stress. Ann Bot 119:1-11

Nile SH, Nile AS, Keum YS (2017) Total phenolics, antioxidant, antitumor, and enzyme inhibitory activity of Indian medicinal and aromatic plants extracted with different extraction methods. 3 Biotech 7:76

Oksman-Caldentey KM, Inze D (2004) Plant cell factories in the post-genomic era: new ways to produce designer secondary metabolites. Trends Plant Sci 9:433-444

Pakdaman N, Ghaderian SM, Ghasemi R, Asemaneh T (2013) Effects of calcium/ magnesium quotients and nickel in the growth medium on growth and nickel accumulation in Pistacia atlantica. J Plant Nutr 36:1708-1718

Pedan V, Fischer N, Rohn S (2016) An online NP-HPLC-DPPH method for the determination of the antioxidant activity of condensed polyphenols in cocoa. Food Res Int 89:890-900

Picot MC, Zengin G, Mollica A, Stefanucci A, Carradori S, Mahomoodally M (2017) In vitro and in silico studies of mangiferin from Aphloia theiformis on key enzymes linked to diabetes type 2 and associated complications. Med Chem 13:633-640

Porter LJ, Hrstich LN, Chan BG (1985) The conversion of procyanidins and prodelphinidins to cyanidin and delphinidin. Phytochemistry 25:223-230

Prior RL, Wu X (2006) Anthocyanins: structural characteristics that result in unique metabolic patterns and biological activities. Free Radical Res 40:1014-1028

Puchchakayala G, Podili L, Bobbala D, Thirupathi K, Boini K, Yellu N, Bobbala R, Gottemukkala K, Pragada R (2008) Antinociceptive and anti-inflammatory effects of Cleome chelidonni linn. roots in experimental animals. Pharmacogn Mag 4:32-36

Quispe C, Viveros-Valdez E, Schmeda-Hirschmann G (2012) Phenolic constituents of the Chilean herbal tea Fabiana imbricata R. et P. Plant Foods Hum Nutr 67:242-246

Ramadan MF, Sharanabasappa G, Seetharam YN, Seshagiri M, Moersel JT (2006) Characterisation of fatty acids and bioactive compounds of kachnar (Bauhinia purpurea L.) seed oil. Food Chem 98:359-365

Rauter AP, Dias C, Martins A, Branco I, Neng NR, Nogueira JM, Goulart M, Silva FV, Justino J, Trevitt C, Waltho JP (2012) Non-toxic Salvia sclareoides Brot. extracts as a source of functional food ingredients: phenolic profile, antioxidant activity and prion binding properties. Food Chem 132:1930-1935

Seabra IJ, Chim RB, Salqueiro P, Braga ME, de Sousa HC (2018) Influence of solvent additives on the aqueous extraction of tannins from pine bark: potential extracts for leather tanning. J Chem Technol Biotechnol 93:1169-1182

Sierra-Cantor JF, Guerrero-Fajardo CA (2017) Methods for improving the cold flow properties of biodiesel with high saturated fatty acids content: a review. Renew Sustain Energy Rev 72:774-790

Singh H, Mishra A, Mishra AK (2018) The chemistry and pharmacology of Cleome genus: a review. Biomed Pharmacother 101:37-48

Smith MA, Dauk M, Ramadan H, Yang H, Seamons LE, Haslam RP, Beaudoin F, Ramirez-Erosa I, Forseille L (2013) Involvement of Arabidopsis ACYLCOENZYME A DESATURASE-LIKE2 (At2g31360) in the biosynthesis of the very-long-chain monounsaturated fatty acid components of membrane lipids. Plant Physiol 161:81-96

Sreelatha S, Padma PR (2009) Antioxidant activity and total phenolic content of Moringa oleifera leaves in two stages of maturity. Plant Foods Hum Nutr 64:303

Williams LAD, Vasques E, Reid W, Porter R, Kraus W (2003) Biological activities of an extract from Cleome viscosa L. (Capparaceae). Naturwissenschaften 90:468-472

Xiao L, Mjøs SA, Haugsgjerd BO (2012) Efficiencies of three common lipid extraction methods evaluated by calculating mass balances of the fatty acids. J Food Compos Anal 25:198-207

Zhu L, Chen J, Tan J, Liu X, Wang B (2017) Flavonoids from Agrimonia pilosa Ledeb: free radical scavenging and DNA oxidative damage protection activities and analysis of bioactivity-structure relationship based on molecular and electronic structures. Molecules 22:195-206 